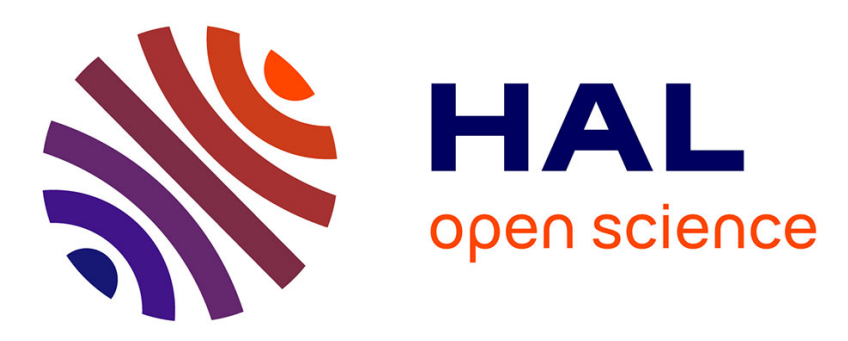

\title{
Size-Dependent Dissociation of Carbon Monoxide on Cobalt Nanoparticles
}

Anders Tuxen, Sophie Carenco, Mahati Chintapalli, Cheng-Hao Chuang, Carlos Escudero, Elzbieta Pach, Peng Jiang, Ferenc Borondics, Brandon Beberwyck, A. Paul Alivisatos, et al.

\section{To cite this version:}

Anders Tuxen, Sophie Carenco, Mahati Chintapalli, Cheng-Hao Chuang, Carlos Escudero, et al.. Size-Dependent Dissociation of Carbon Monoxide on Cobalt Nanoparticles. Journal of the American Chemical Society, 2013, 135 (6), pp.2273-2278. 10.1021/ja3105889 . hal-02384068

\section{HAL Id: hal-02384068 https://hal.sorbonne-universite.fr/hal-02384068}

Submitted on 26 May 2021

HAL is a multi-disciplinary open access archive for the deposit and dissemination of scientific research documents, whether they are published or not. The documents may come from teaching and research institutions in France or abroad, or from public or private research centers.
L'archive ouverte pluridisciplinaire HAL, est destinée au dépôt et à la diffusion de documents scientifiques de niveau recherche, publiés ou non, émanant des établissements d'enseignement et de recherche français ou étrangers, des laboratoires publics ou privés. 


\title{
Size-Dependent Dissociation of Carbon Monoxide on Cobalt Nanoparticles
}

\author{
Anders Tuxen, ${ }^{\dagger}$ Sophie Carenco, ${ }^{\dagger}$ Mahati Chintapalli, ${ }^{\dagger, \dagger}$ Cheng-Hao Chuang, ${ }^{\S, \|}$ Carlos Escudero, ${ }^{\dagger}$ \\ Elzbieta Pach, ${ }^{\dagger}$ Peng Jiang, ${ }^{\dagger}$ Ferenc Borondics, ${ }^{\dagger}$ Brandon Beberwyck ${ }^{\dagger, \perp}$ A. Paul Alivisatos, ${ }^{\dagger, \perp}$ \\ Geoff Thornton, ${ }^{\dagger} \#$ Way-Faung Pong, ${ }^{\|}$Jinghua Guo, ${ }^{\S}$ Ruben Perez, ${ }^{\dagger}$ Flemming Besenbacher, ${ }^{\nabla}$ \\ and Miquel Salmeron ${ }^{* \dagger}$ \\ ${ }^{\dagger}$ Material Sciences Division, Lawrence Berkeley National Laboratory, 1 Cyclotron Road, Berkeley, California 94720, United States \\ ${ }^{\ddagger}$ Department of Materials Science and Engineering, University of California, Berkeley, California 94720, United States \\ ${ }^{\S}$ Advanced Light Source, Lawrence Berkeley National Laboratory, 1 Cyclotron Road, Berkeley, California 94720, United States \\ "Department of Physics, Tamkang University, Tamsui, Taiwan 250, R. O. C. \\ ${ }^{\perp}$ Department of Chemistry, University of California, Berkeley, California 94720, United States \\ \#London Centre for Nanotechnology and Department of Chemistry, University College London, 20 Gordon Street, \\ London WC1H 0AJ, U.K. \\ ${ }^{\nabla}$ Interdisciplinary Nanoscience Center (iNANO) and Department of Physics and Astronomy, Aarhus University, DK-8000 Aarhus C, \\ Denmark
}

\begin{abstract}
In situ soft X-ray absorption spectroscopy (XAS) was employed to study the adsorption and dissociation of carbon monoxide molecules on cobalt nanoparticles with sizes ranging from 4 to $15 \mathrm{~nm}$. The majority of CO molecules adsorb molecularly on the surface of the nanoparticles, but some undergo dissociative adsorption, leading to oxide species on the surface of the nanoparticles. We found that the tendency of CO to undergo dissociation depends critically on the size of the Co nanoparticles. Indeed, CO molecules dissociate much more efficiently on the larger nanoparticles $(15 \mathrm{~nm})$ than on the smaller particles (4 nm). We further observed a strong increase in the dissociation rate of adsorbed $\mathrm{CO}$ upon exposure to hydrogen, clearly demonstrating that the CO dissociation on cobalt nanoparticles is assisted by hydrogen. Our results suggest that the ability of cobalt nanoparticles to dissociate hydrogen is the main parameter determining the reactivity of cobalt nanoparticles in Fischer-Tropsch synthesis.
\end{abstract}

\section{INTRODUCTION}

Fischer-Tropsch synthesis (FTS) is an attractive way to produce liquid hydrocarbons as an alternative to fuels derived from crude oil. In FTS, metallic particles of $\mathrm{Ni}, \mathrm{Fe}, \mathrm{Ru}$, or Co constitute the active phase for the reduction of $\mathrm{CO}$ by $\mathrm{H}_{2}$. The detailed atomic-scale mechanism in the FT reaction has been and is still being discussed extensively in the literature. ${ }^{1}$ One of the main controversies in FTS is related to the initial step where the CO molecule adsorbs and dissociates on the surface of the metal catalyst. Fischer and Tropsch originally proposed the carbide mechanism, wherein $\mathrm{CO}$ undergoes direct dissociation upon adsorption, resulting in $\mathrm{C}$ and $\mathrm{O}$ adspecies. ${ }^{2-6}$ Recently this model has been supported by ab initio density functional theory (DFT) calculations on high Miller index $\mathrm{Ru}$ and Co surfaces. ${ }^{7,8}$ However, another model suggests that the dissociation of $\mathrm{CO}$ is hydrogen-assisted in the sense that hydrogen adsorbed on the catalyst facilitates the dissociation of the triple bond of $\mathrm{CO} .{ }^{9-11}$ In this case, the dissociation goes through a $-\mathrm{COH},-\mathrm{HCO}$, or $-\mathrm{H}_{2} \mathrm{CO}$ intermediate, which lowers the activation energy for $\mathrm{CO}$ dissociation. ${ }^{12}$ Experimentally, the hydrogen-assisted model has been supported by the results of Ojeda and co-workers, who measured the kinetic isotope effect on the reaction rate. ${ }^{13,14}$ Alternatively, a CO insertion mechanism producing formate on the surface was proposed, ${ }^{26}$ but the role of these species in product formation was not asserted. ${ }^{27}$ One of the main reasons why controversies about the $\mathrm{CO}$ dissociation mechanism still exist is that the surface species involved are extremely difficult to identify experimentally because they are short-lived and thus are present in very small concentrations on the surface of the particles. Moreover, the detection of these surface species requires surface science techniques capable of operating in situ under high pressure and high temperature. 
Another central question in FTS is the influence of the size of the nanoparticles on the reactivity. It is well-known that the intrinsic reactivity of both Co and Ru nanoparticles is relatively constant in the $10-15 \mathrm{~nm}$ size regime, but decreases rapidly when the particle size is reduced below $8 \mathrm{~nm}$. However, the fundamental principles underlying this size effect are still under debate. $^{15-19}$

In this work, we used in situ X-ray absorption spectroscopy (XAS) to study Co nanoparticles in the $4-15 \mathrm{~nm}$ size regime at pressures of up to $1 \mathrm{~atm}$. We present direct spectroscopic evidence showing that the dissociation of $\mathrm{CO}$ on cobalt nanoparticles is assisted by hydrogen. Moreover, our results reveal that the dissociation of $\mathrm{CO}$ is closely linked to the size of the nanoparticles, since larger Co nanoparticles dissociate $\mathrm{CO}$ much more effectively than smaller ones. Our results suggest that ineffective dissociation of hydrogen is responsible for the reduced reactivity of the smallest cobalt nanoparticles in FTS.

\section{EXPERIMENTAL SECTION}

The XAS experiments were performed on beamline 7.0.1 at the Advanced Light Source (Berkeley, CA) using an energy resolution of $0.2 \mathrm{eV}$ on both the Co L-edge and the $\mathrm{O}$ K-edge, except for the experiments presented in Figure 5, which were done on beamline 6.3.1 with an energy resolution of $0.5 \mathrm{eV}$. All of the measurements were recorded in the total-electron-yield detection mode, making the XAS measurements sensitive to the first few nanometers of the samples. We used a specially designed gas cell with a $\sim 100 \mathrm{~nm}$ thick $\mathrm{Si}_{3} \mathrm{~N}_{4}$ nitride window separating the high-pressure reactor volume from the beamline. ${ }^{20}$ The sample was heated using a $975 \mathrm{~nm}$ IR fiber-optic laser that heats the gold foil coated with nanoparticles. The nanoparticles were prepared by colloidal chemistry methods according to ref 21 . The nanoparticles were deposited on the gold foil using the Langmuir-Blodgett technique. Extensive care was taken to prevent the formation of nickel carbonyls, and all parts in the reactor cell that would come into contact with $\mathrm{CO}$ were constructed from copper- or gold-coated components. All of the measurements were conducted in flow mode with a flow rate of $40 \mathrm{~mL} / \mathrm{min}$ for the reactive gas. Scanning electron microscopy (SEM) using a Zeiss Gemini Ultra-55 instrument was performed on the cobalt nanoparticles both before and after the XAS measurements.

\section{RESULTS AND DISCUSSION}

To study the adsorption of $\mathrm{CO}$ on cobalt nanoparticles as a function of particle size, we employed the cobalt nanoparticles depicted in the SEM images in the upper panel of Figure 1, which all displayed narrow size distributions. Before being exposed to $\mathrm{CO}$, the nanoparticles were oxidized in situ under $1 \mathrm{~atm} \mathrm{O}_{2}$ at $200{ }^{\circ} \mathrm{C}$ for $5 \mathrm{~min}$ to remove all carbon impurities from the particles. The bottom spectrum in the lower panel of Figure 1 shows the Co L-edge for the $10 \mathrm{~nm}$ Co nanoparticles after this treatment. The peak at $780 \mathrm{eV}$ and the shoulder at $778.5 \mathrm{eV}$ reveal that the cobalt nanoparticles were in the $\mathrm{Co}_{3} \mathrm{O}_{4}$ state after the oxidation treatment. The gas flow was then switched to $1 \mathrm{~atm} \mathrm{H}_{2}$ at room temperature (RT). This reduced the nanoparticles to $\mathrm{CoO}$ (Figure 1, second spectrum from the bottom), as shown by the features at 776.5 and $781 \mathrm{eV}^{22}$ Further annealing to $250{ }^{\circ} \mathrm{C}$ in $\mathrm{H}_{2}$ reduced the nanoparticles completely to metallic $\mathrm{Co}$, as revealed by the single asymmetric absorption peak at $778.0 \mathrm{eV}$ (top spectrum). The Co nanoparticles were thus reduced in the sequence $\mathrm{Co}_{3} \mathrm{O}_{4} \rightarrow \mathrm{CoO} \rightarrow$ $\mathrm{Co}^{0}$ as observed in ref 23. We observed similar behavior for the 4 and $15 \mathrm{~nm}$ particles (data not shown), which were also completely reduced to metallic Co at $250{ }^{\circ} \mathrm{C}$.

After reducing the nanoparticles to the metallic state in $\mathrm{H}_{2}$, we exposed them to $1: 1$ (by flow rate) $\mathrm{CO} / \mathrm{He}(1 \mathrm{~atm})$ at $\mathrm{RT}$
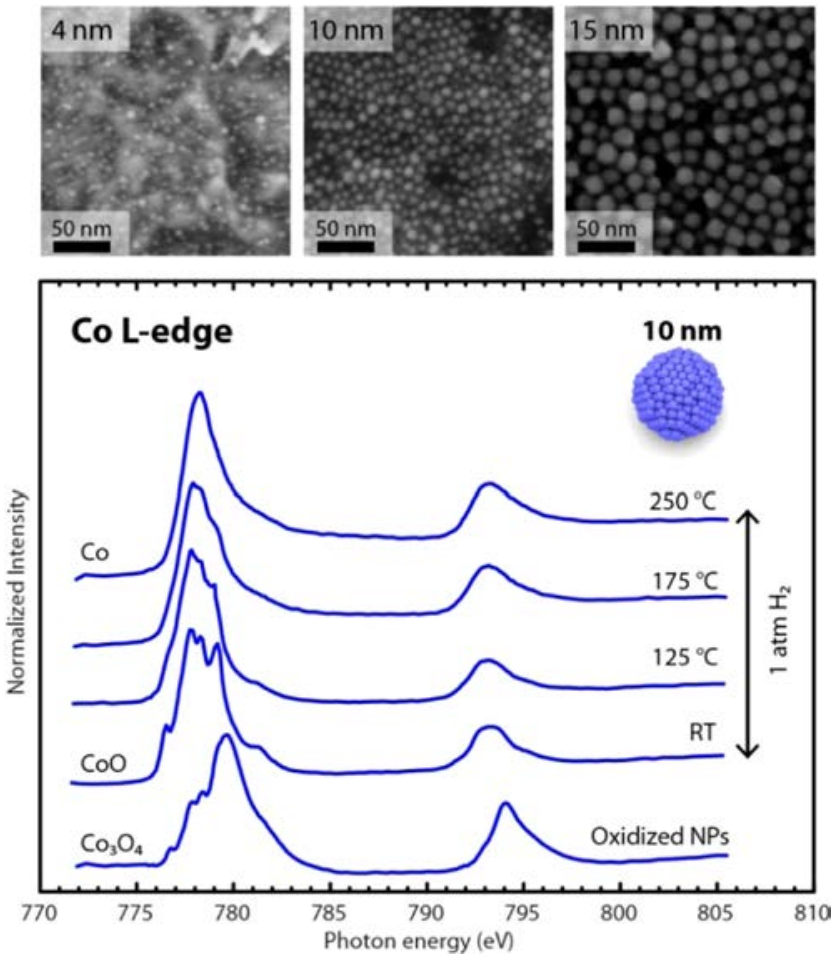

Figure 1. (top) SEM images of the 4, 10, and $15 \mathrm{~nm}$ cobalt nanoparticles used in this study. (bottom) XAS spectra of the Co L-edge during the reduction of the $10 \mathrm{~nm}$ nanoparticles in pure $\mathrm{H}_{2}$ at increasing temperature.

for $5 \mathrm{~min}$. We then replaced the $\mathrm{CO} / \mathrm{He}$ mixture with pure $\mathrm{He}$ to avoid any contribution to the XAS spectra from gas-phase $\mathrm{CO}$. The spectrum in the left panel of Figure 2 shows the O Kedge XAS results for the 4, 10, and $15 \mathrm{~nm}$ nanoparticles. The spectrum of the $15 \mathrm{~nm}$ nanoparticles at RT reveals XAS peaks that are typical of $\mathrm{CO}$ adsorbed on cobalt. In particular, an intense $\pi^{*}$ transition at $534.2 \mathrm{eV}$ and a weak $\sigma^{*}$ transition at $550 \mathrm{eV}$ were observed. ${ }^{19}$ We assign these features to $\mathrm{CO}$ molecules adsorbed molecularly on the cobalt nanoparticles. However, there is also a clear XAS peak at approximately 531 $\mathrm{eV}$ that cannot be assigned to molecular $\mathrm{CO}$. Instead, the energy of this peak is very close to that of the $\mathrm{X}$-ray absorption edge of the bulk cobalt oxides $\mathrm{CoO}$ and $\mathrm{Co}_{3} \mathrm{O}_{4}$, as confirmed by comparison to the $\mathrm{O}$ K-edge of bulk oxide references (data not shown). This oxide peak is rather broad and may therefore arise from a mixture of the two oxides; we thus refer to it as the $\mathrm{CoO}_{x}$ peak. The formation of a surface oxide under these conditions was further confirmed by the XAS spectra on the Co L-edge (Figure 2, right panel). Here, the spectrum taken after exposure to $\mathrm{CO} / \mathrm{He}$ at RT clearly shows small XAS features at 776.5, 779, and $781 \mathrm{eV}$. The formation of this $\mathrm{CoO}_{x}$ phase is even more clearly seen for the particles annealed to $250{ }^{\circ} \mathrm{C}$ under $\mathrm{CO} / \mathrm{He}$, after which very clear features from the surface oxide were observed on both the O K-edge and the Co L-edge.

The formation of this surface oxide on the cobalt nanoparticles in the presence of pure $\mathrm{CO}$ directly shows that a substantial fraction of the $\mathrm{CO}$ molecules undergo dissociative adsorption, producing surface oxygen and carbon. This does not exclude the possibility that other processes such as $\mathrm{CO}$ insertion could occur on the surface at the same time, although the resulting species could not be observed here. Interestingly, we found that the intensity of the oxide peak, and thus the tendency for $\mathrm{CO}$ to dissociate, depends directly on the actual size of the nanoparticles, 

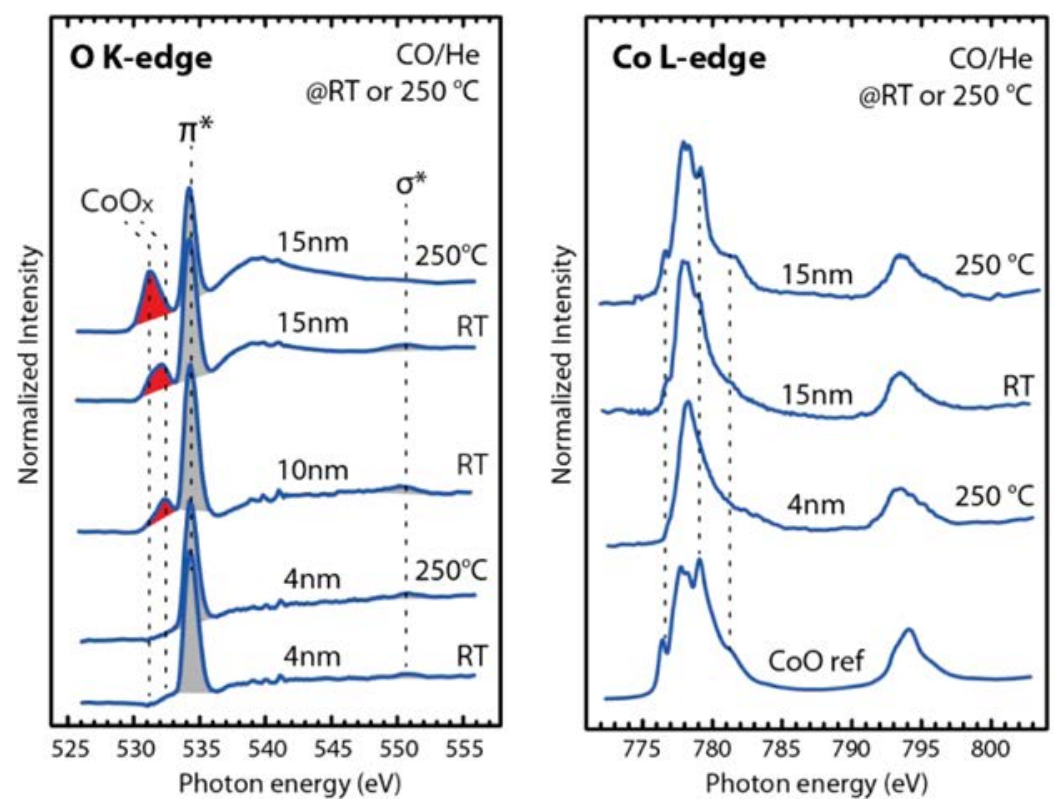

Figure 2. (left) $\mathrm{O}$ K-edge for reduced 4,10 , and $15 \mathrm{~nm}$ cobalt nanoparticles after exposure to $1: 1 \mathrm{CO} / \mathrm{He}$ at $\mathrm{RT}$ and $250{ }^{\circ} \mathrm{C}$. (right) Co L-edge for 4 and $15 \mathrm{~nm}$ nanoparticles under the same conditions as for the $\mathrm{O}$ K-edge.

as shown in the left panel of Figure 2. The oxide peak is very pronounced for the $15 \mathrm{~nm}$ nanoparticles but is smaller for the $10 \mathrm{~nm}$ nanoparticles and essentially undetectable for the $4 \mathrm{~nm}$ nanoparticles both at RT and at $250{ }^{\circ} \mathrm{C}$, which is in agreement with the results reported in ref 19 . These observations are directly supported by the measurements on the Co L-edge (Figure 2, right panel), which showed no oxide formation on the $4 \mathrm{~nm}$ nanoparticles (even at $250{ }^{\circ} \mathrm{C}$ ), in contrast to the $15 \mathrm{~nm}$ nanoparticles, where oxide formation was clearly seen. By measuring the area of the surface oxide peak relative to that of the $\pi^{*}$ peak in the O K-edge XAS spectra, we can estimate the relative amounts of oxide and remaining $\mathrm{CO}$ molecules on the nanoparticles and thus the ability of the nanoparticles to dissociate CO. Figure 3 shows these values for the 4, 10, and $15 \mathrm{~nm}$

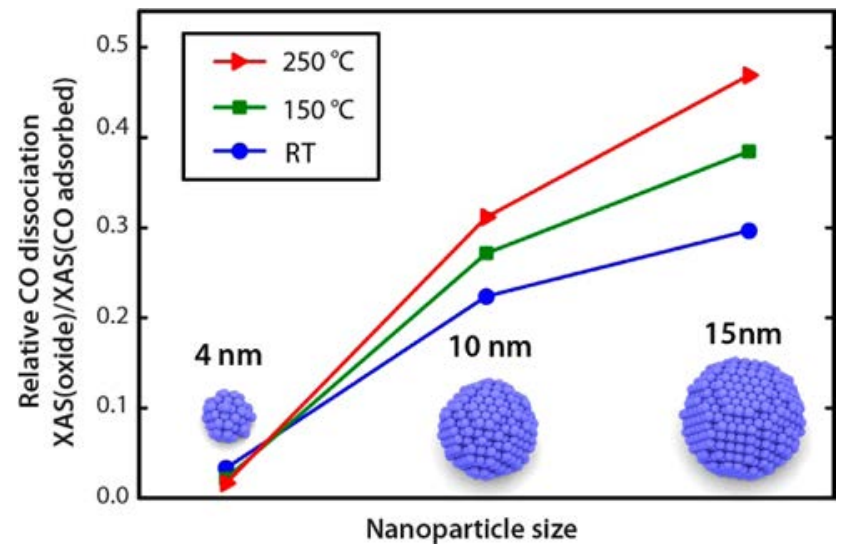

Figure 3. Relative concentration of dissociated $\mathrm{CO}$ species on 4, 10, and $15 \mathrm{~nm}$ nanoparticles after exposure to $\mathrm{CO} / \mathrm{He}$ at different temperatures. The relative concentration was calculated as the ratio of the areas of the oxide XAS peak and the $\pi^{*}$ peak from intact adsorbed CO.

cobalt nanoparticles after exposure to the $\mathrm{CO} / \mathrm{He}$ mixture at RT, $150{ }^{\circ} \mathrm{C}$, and $250{ }^{\circ} \mathrm{C}$. It can be seen that the relative amount of oxide versus adsorbed molecular $\mathrm{CO}$ depends directly on the nanoparticle size: no dissociation occurs on the smallest $(4 \mathrm{~nm})$ nanoparticles, while a substantial fraction of the adsorbed CO molecules undergoes dissociation on the largest $(15 \mathrm{~nm})$ nanoparticles. Figure 3 also reveals that there is a clear increase in the oxide proportion with temperature, indicating that the oxide formation and thus the $\mathrm{CO}$ dissociation is a thermally activated process.

To gain further understanding of why the smallest nanoparticles display a very low ability to dissociate $\mathrm{CO}$, we again exposed the $4 \mathrm{~nm}$ particles successively to $\mathrm{CO} / \mathrm{He}$ and then pure He. At RT and $250{ }^{\circ} \mathrm{C}$ (Figure $4 \mathrm{a}, \mathrm{b}$, respectively), we observed again that the $\mathrm{CO}$ remains intact and molecularly adsorbed on the nanoparticles in the presence of He. Hence, there is no dissociation of $\mathrm{CO}$ in the absence of hydrogen. We subsequently switched the gas flow to pure $\mathrm{H}_{2}$ and immediately observed a clear adsorption peak at $531.0 \mathrm{eV}$, which can be assigned to dissociated $\mathrm{CO}$ species, as discussed previously. The photon energy of this peak is not consistent with water, which is a byproduct of the FT reaction and thus may have formed when the adsorbed $\mathrm{CO}$ molecules are exposed to $\mathrm{H}_{2}$. In addition, since the measurements were performed in flow mode, any water in the reactor would have been removed from the reactor volume. ${ }^{19}$ Figure $4 \mathrm{c}$ reveals how the area of the oxide peak increases when the adsorbed $\mathrm{CO}$ is exposed to $\mathrm{H}_{2}$. The experimental data thus show that the addition of $\mathrm{H}_{2}$ immediately leads to dissociation of the adsorbed $\mathrm{CO}$ molecules, thus supporting the hydrogen-assisted CO dissociation mechanism discussed in the Introduction as opposed to the direct dissociation pathway.

In Figure 4d, we show the area of the $\mathrm{CO} \pi^{*}$ peak as a function of time at RT, $150{ }^{\circ} \mathrm{C}$, and $250{ }^{\circ} \mathrm{C}$. On the basis of these measurements, we calculate for the $4 \mathrm{~nm}$ NPs an activation energy of $23.7 \mathrm{~kJ} / \mathrm{mol}$ for the hydrogen-assisted dissociation of $\mathrm{CO}$ in $\mathrm{H}_{2}$ using the Arrhenius equation. This value, which is substantially lower than the activation energy for the formation of methane $(90-100 \mathrm{~kJ} / \mathrm{mol}){ }^{19}$ shows that CO dissociation, while important, is not the rate-limiting step in the formation of methane under these conditions. Moreover, this value is significantly lower than the values computed for a 

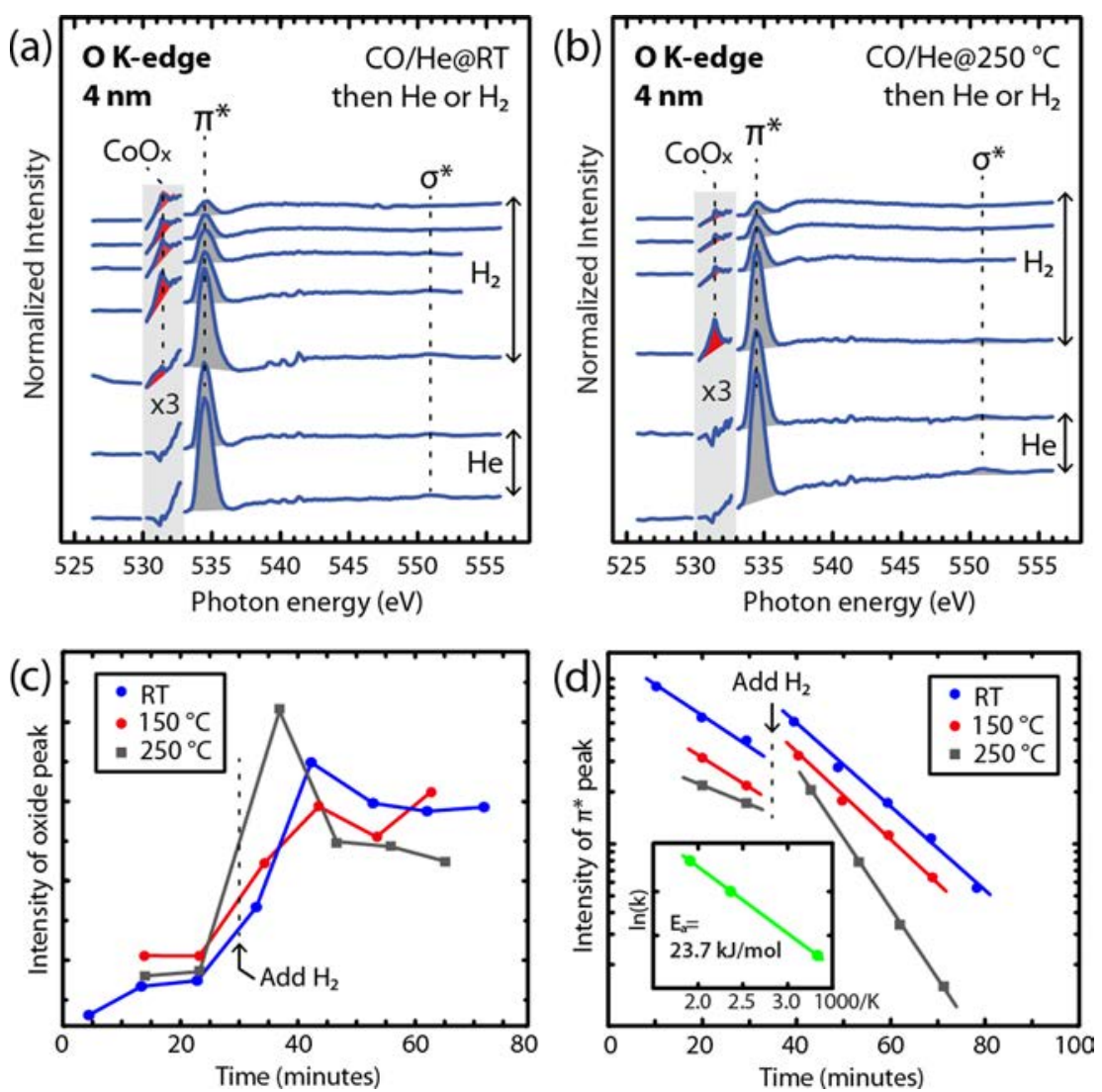

Figure 4. (a, b) $\mathrm{O}$ K-edge spectra of $4 \mathrm{~nm}$ particles after exposure to $\mathrm{CO} / \mathrm{He}$ followed by pure $\mathrm{He}$ and then pure $\mathrm{H}_{2}$ at (a) $\mathrm{RT}$ and (b) $250{ }^{\circ} \mathrm{C}$. The time between each spectrum was approximately $10 \mathrm{~min}$. (c, d) Areas of the (c) $\mathrm{CoO}_{x}$ and (d) $\pi^{*}$ peaks as functions of time are shown for three different temperatures. The logarithmic ordinate scale in this case should be noted. The inset in (d) shows an Arrhenius plot obtained using the slopes of the previous curves, indicating an activation energy of $23.7 \mathrm{~kJ} / \mathrm{mol}$ for the hydrogen-assisted CO dissociation.
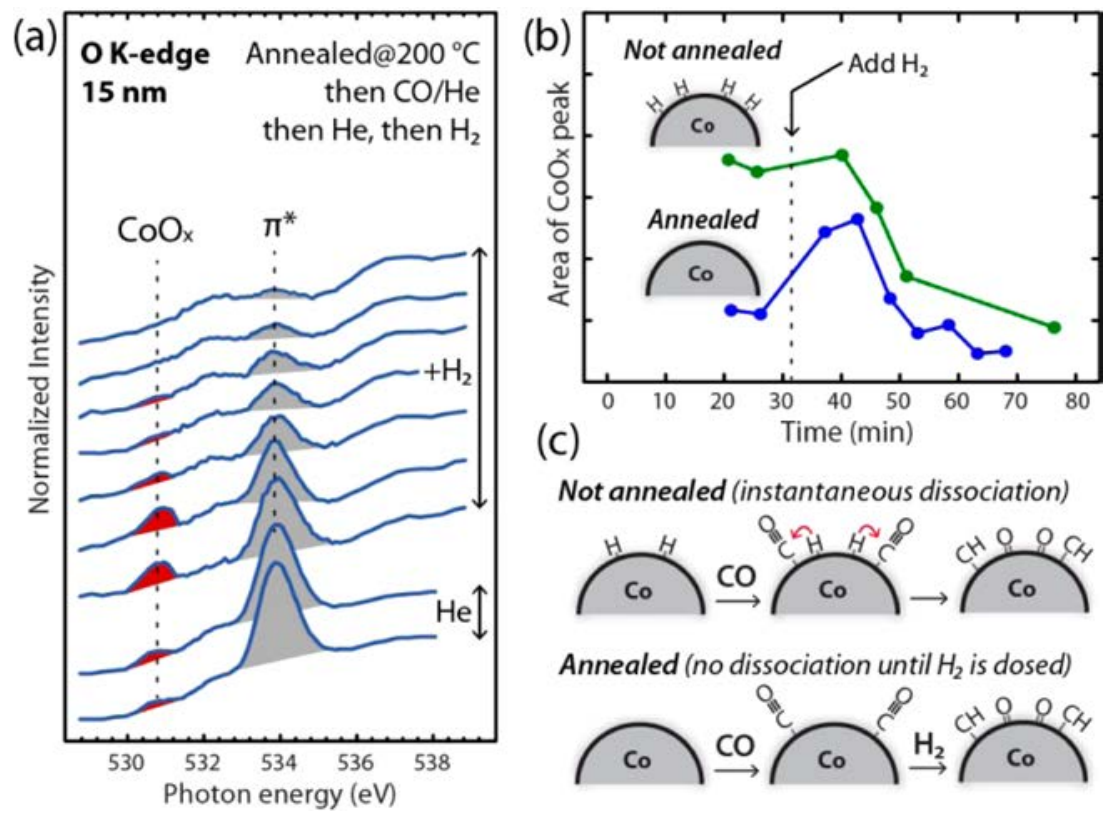

Not annealed (instantaneous dissociation)

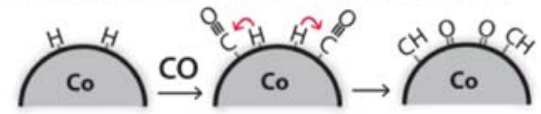

Annealed (no dissociation until $\mathrm{H}_{2}$ is dosed)

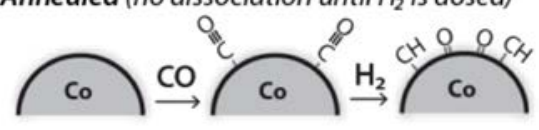

Figure 5. (a) $\mathrm{O}$ K-edge spectra of $15 \mathrm{~nm}$ cobalt nanoparticles after preannealing in $\mathrm{He}$ at $200{ }^{\circ} \mathrm{C}$ and subsequent exposure to $\mathrm{CO} / \mathrm{He}$ and then $\mathrm{H}_{2}$. (b) Areas of the $\mathrm{CoO}_{x}$ peaks from dissociation experiments on nanoparticles with (blue points) and without preannealing (green points). (c) Schematic illustration of $\mathrm{CO}$ dissociation in the two different experiments.

$\mathrm{Co}(0001)$ surface $\left(90\right.$ and $68 \mathrm{~kJ} / \mathrm{mol}$ for $\mathrm{HCO}$ and $\mathrm{H}_{2} \mathrm{CO}$ formation, respectively), ${ }^{25}$ highlighting the likely role of steps and defects in the $\mathrm{CO}$ dissociation process.
The observation that $\mathrm{CO}$ dissociation is assisted by hydrogen provides a direct explanation for the size-dependent dissociation that we observed on the 4,10 , and $15 \mathrm{~nm}$ particles. 
Herranz et al. ${ }^{19}$ demonstrated that the ability of Co nanoparticles to dissociate hydrogen decreases with the particle size. In particular, $\mathrm{H}-\mathrm{D}$ exchange experiments conducted on reduced Co NPs suggested that the increase in turnover frequency for $\mathrm{CH}_{4}$ formation with 3-10 nm NPs could be linked with the increase in $\mathrm{H}_{2}$ dissociation activity. Accordingly, the amount of dissociated hydrogen on the surface of the nanoparticles is expected to be substantially higher on the largest nanoparticles compared with the smallest particles, meaning that more hydrogen is available to assist the dissociation of $\mathrm{CO}$ on the largest particles. This explains the trend in Figure 3 that larger nanoparticles dissociate $\mathrm{CO}$ more effectively.

To obtain further proof that hydrogen adsorbed on the surface of the nanoparticles is responsible for the dissociation of $\mathrm{CO}$, we performed an experiment in which the $15 \mathrm{~nm}$ nanoparticles were preannealed to $200{ }^{\circ} \mathrm{C}$ in $\mathrm{He}$ for $10 \mathrm{~min}$ before exposure to $\mathrm{CO}$ to remove adsorbed hydrogen from the surface of the nanoparticles. The two spectra at the bottom of Figure 5a reveal that the large nanoparticles in this experiment displayed little ability to dissociate $\mathrm{CO}$, as evidenced by the very low amount of $\mathrm{CoO}_{x}$. However, when the nanoparticles were exposed to $\mathrm{H}_{2}$, the oxide peak increased substantially, revealing that the dosed hydrogen induces the dissociation of $\mathrm{CO}$. Figure $5 \mathrm{~b}$ shows the area of the oxide peak for the experiment with the preannealed nanoparticles (Figure 5a) along with that for a control experiment in which the nanoparticles were not preannealed. It is clearly seen that $\mathrm{CO}$ dissociated immediately when the nanoparticles were not preannealed (green points), while dissociation did not occur on the preannealed nanoparticles until $\mathrm{H}_{2}$ was dosed (blue points). These experiments clearly confirm that residual hydrogen adsorbed on the surface of the nanoparticles is responsible for the dissociation of $\mathrm{CO}$ even on the larger nanoparticles.

The lower coverage of dissociated hydrogen on the small nanoparticles is expected not only to reduce the ability of the nanoparticles to dissociate $\mathrm{CO}$ but also to slow the further reaction of the $\mathrm{CH}_{x}$ fragments produced from the dissociation. This is in good agreement with the SSTIKA experiments performed by den Breejen et al., ${ }^{17}$ who found an increase in the surface residence time for $\mathrm{CH}_{x}$ on cobalt nanoparticles smaller than $6 \mathrm{~nm}$. Also, the coverage of $\mathrm{CH}_{x}$ on the surface on the particles was found to decrease with particle size, which can be explained by a reduced $\mathrm{CO}$ dissociation rate due to a smaller amount of dissociated hydrogen. Carballo et al. ${ }^{24}$ observed a similar effect on $\mathrm{Ru}$ nanoparticles, which they explained in terms of stronger adsorption of $\mathrm{CO}$ due to the larger d-orbital local density of states in the smaller particles and thus the larger degree of back-bonding between $\mathrm{d}$ orbitals and the antibonding $\pi^{*}$ orbital in the $\mathrm{CO}$ molecule, which strengthens the $\mathrm{Ru}-\mathrm{C}$ bond. However, stronger binding of $\mathrm{CO}$ does not alone explain our results, since stronger adsorption would weaken the $\mathrm{C}-\mathrm{O}$ bond and thus lead to an increase in $\mathrm{CO}$ dissociation with decreasing cluster size. In fact, in our experiments we observed the opposite effect, since smaller particles display a reduced tendency to dissociate $\mathrm{CO}$. Instead, the reduced tendency to dissociate $\mathrm{CO}$ with decreasing particle size must be an effect of the reduced ability of the particles to dissociate $\mathrm{H}_{2}$, which is a necessary first step. The reaction pathway of the adsorbed hydrogen with adsorbed $\mathrm{CO}$ is still unclear, as is its indirect effect on the adsorption energy of the different species. Dedicated DFT modeling will be required to elucidate the size-dependent $\mathrm{H}$-assisted $\mathrm{CO}$ dissociation mechanism and to identify the reaction intermediates.

\section{SUMMARY}

By studying cobalt nanoparticles with in situ soft X-ray absorption spectroscopy, we have demonstrated that the dissociation of $\mathrm{CO}$ is facilitated by hydrogen. Our experimental data thus support the hydrogen-assisted model. We suggest that the dissociation occurs through a $-\mathrm{COH}$ or $-\mathrm{CH}_{x} \mathrm{O}$ intermediate, although such intermediates were not directly identified by XAS. We also observed a clear size-dependent ability of the nanoparticles to dissociate $\mathrm{CO}$, with smaller nanoparticles favoring molecular adsorption of $\mathrm{CO}$ and larger nanoparticles favoring $\mathrm{CO}$ dissociation. Importantly, our results indicate that it is the ability of the nanoparticles to dissociate hydrogen that determines their ability to dissociate $\mathrm{CO}$ via the hydrogen-assisted mechanism. This explains the well-known effect that the intrinsic reactivity in FTS decreases when the nanoparticle size decreases below $10 \mathrm{~nm}$.

\section{AUTHOR INFORMATION}

\section{Corresponding Author}

mbsalmeron@lbl.gov

Notes

The authors declare no competing financial interest.

\section{ACKNOWLEDGMENTS}

This work was supported by the Director, Office of Science, Office of Basic Energy Sciences, Chemical Sciences, Geosciences, and Biosciences Division, under Department of Energy Contract DE-AC02-05CH11231. The authors further acknowledge User Proposal 994 at the Molecular Foundry and the Advanced Light Source for allocated beamtime. A.T. gratefully acknowledges the postdoc stipend "In-Situ Investigations of Nanoparticles for Fischer-Tropsch Catalysis" from the Danish Research Council for Independent Research I Natural Sciences. G.T. acknowledges support from the EPSRC (U.K.). R.P. acknowledges the financial support of the Spanish MEC (Project PR2011-0402), Fundación CajaMadrid and the UAM-Banco Santander Program of Collaboration with the USA. This material is based upon work supported by the National Science Foundation Graduate Research Fellowship under Grant No. DGE1106400.

\section{REFERENCES}

(1) Shetty, S.; van Santen, R. A. Catal. Today 2011, 171, 168.

(2) Fischer, F.; Tropsch, H. Brennst.-Chem. 1930, 11, 489.

(3) Fischer, F.; Tropsch, H. Brennst.-Chem. 1926, 7, 97.

(4) Schulz, H. Appl. Catal., A 1999, 186, 3.

(5) Davis, B. H. Catal. Today 2009, 141, 25.

(6) Bell, A. T. Catal. Rev. 1981, 23, 203.

(7) Shetty, S.; Jansen, A. P. J.; van Santen, R. A. J. Am. Chem. Soc. 2009, 131, 12874.

(8) Shetty, S.; van Santen, R. A. Phys. Chem. Chem. Phys. 2010, 12, 6330.

(9) van Helden, P.; van den Berg, J. A.; Ciobica, I. M. Catal. Sci. Technol. 2012, 2, 491.

(10) Blyholder, G.; Lawless, M. Langmuir 1991, 7, 140.

(11) Inderwildi, O. R.; Jenkins, S. J.; King, D. A. J. Phys. Chem. C 2008, 112, 1305.

(12) Andersson, M. P.; Abild-Pedersen, F.; Remediakis, I. N.; Bligaard, T.; Jones, G.; Engbæk, J.; Lytken, O.; Horch, S.; Nielsen, J. H.; Sehested, J.; Rostrup-Nielsen, J. R.; Nørskov, J. K.; Chorkendorff, I. J. Catal. 2008, 255, 6.

(13) Ojeda, M.; Li, A. W.; Nabar, R.; Nilekar, A. U.; Mavrikakis, M.; Iglesia, E. J. Phys. Chem. C 2010, 114, 19761.

(14) Ojeda, M.; Nabar, R.; Nilekar, A. U.; Ishikawa, A.; Mavrikakis, M.; Iglesia, E. J. Catal. 2010, 272, 287. 
(15) Yang, J.; Tveten, E. Z.; Chen, D.; Holmen, A. Langmuir 2010, 26, 16558.

(16) Prieto, G.; Martinez, A.; Concepcion, P.; Moreno-Tost, R. J. Catal. 2009, 266, 129.

(17) den Breejen, J. P.; Radstake, P. B.; Bezemer, G. L.; Bitter, J. H.; Froseth, V.; Holmen, A.; de Jong, K. P. J. Am. Chem. Soc. 2009, 131, 7197.

(18) Bezemer, G. L.; Bitter, J. H.; Kuipers, H. P. C. E.; Oosterbeek, H.; Holewijn, J. E.; Xu, X. D.; Kapteijn, F.; van Dillen, A. J.; de Jong, K. P. J. Am. Chem. Soc. 2006, 128, 3956.

(19) Herranz, T.; Deng, X. Y.; Cabot, A.; Guo, J. G.; Salmeron, M. J. Phys. Chem. B 2009, 113, 10721.

(20) Escudero, C.; Jiang, P.; Pach, E.; Borondics, F.; West, M. W.; Tuxen, A.; Chintapalli, M.; Carenco, S.; Guo, J.; Salmeron, M. J. Synchrotron Radiat. 2013, in press.

(21) Puntes, V. F.; Krishnan, K. M.; Alivisatos, A. P. Science 2001, $291,2115$.

(22) Morales, F.; de Groot, F. M. F.; Glatzel, P.; Kleimenov, E.; Bluhm, H.; Havecker, M.; Knop-Gericke, A.; Weckhuysen, B. M. J. Phys. Chem. B 2004, 108, 16201.

(23) Tsakoumis, N. E.; Voronov, A.; Ronning, M.; van Beek, W.; Borg, O.; Rytter, E.; Holmen, A. J. Catal. 2012, 291, 138.

(24) Carballo, J. M. G.; Yang, J.; Holmen, A.; Garcia-Rodriguez, S.; Rojas, S.; Ojeda, M.; Fierro, J. L. G. J. Catal. 2011, 284, 102.

(25) Zhuo, M.; Tan, K. F.; Borgna, A.; Saeys, M. J. Phys. Chem. C 2009, 113, 8357.

(26) (a) Pichler, H.; Schulz, H. Chem. Ing. Tech. 1970, 42, 1162. (b) Schweicher, J.; Bundhoo, A.; Kruse, N. J. Am. Chem. Soc. 2012, 134, 16135.

(27) Schweicher, J.; Bundhoo, A.; Frennet, A.; Kruse, N.; Daly, H.; Meunier, F. C. J. Phys. Chem. C 2010, 114, 2248. 